\title{
Comparisons of fast repetition rate fluorescence estimated primary production and ${ }^{14} \mathrm{C}$ uptake by phytoplankton
}

\author{
D. Christopher Melrose ${ }^{1, *}$, Candace A. Oviatt ${ }^{2}$, John E. O'Reilly ${ }^{1}$, Mark S. Berman ${ }^{1}$ \\ ${ }^{1}$ National Marine Fisheries Service 28 Tarzwell Dr., Narragansett, Rhode Island 02882, USA \\ ${ }^{2}$ University of Rhode Island, South Ferry Rd, Narragansett, Rhode Island 02882, USA
}

\begin{abstract}
Comparisons of primary productivity measured by ${ }^{14} \mathrm{C}$ uptake and fast repetition rate fluorescence (FRRF) for samples taken from Massachusetts Bay and Narragansett Bay demonstrated a linear relationship between the 2 techniques. The slope of the regression for different phytoplankton samples ranged between 0.23 and 1.04, with most between 0.4 and 0 . The $\mathrm{r}^{2}$ was usually high and $>0.9$ in the best cases. The results indicated that the FRRF usually underestimated primary productivity relative to ${ }^{14} \mathrm{C}$. The variability in the relationship between ${ }^{14} \mathrm{C}$ uptake and the FRRF productivity estimates indicates that FRRF field measurements should be calibrated against other productivity measurement techniques such as ${ }^{14} \mathrm{C}$ uptake or oxygen production if they are to be compared to historical productivity estimates. The Kolber \& Falkowski (1993; Limnol Oceanogr 38:1646-1665) and the Smyth et al. (2004; J Plankton Res 19:1637-1670) models for estimating productivity by variable fluorescence were compared, and agreed very well with an $\mathrm{r}^{2}$ of 0.99 for the linear relationship between the 2 techniques.
\end{abstract}

KEY WORDS: Variable fluorescence - Primary productivity - Fast repetition rate fluorescence · Phytoplankton

\section{INTRODUCTION}

Variable fluorescence provides a useful procedure for measuring photosynthetic parameters in plants and algae and for estimating photosynthetic rates. This technique presents both potential advantages and pitfalls when compared with traditional chemical measurements of photosynthetic rates. The purpose of this paper was to compare estimates of carbon fixation rates derived from variable fluorescence with those measured using the ${ }^{14} \mathrm{C}$ method under laboratory conditions.

Traditionally, primary production has been measured chemically. One approach is to measure rates of photosynthetic oxygen evolution, such as in the light and dark bottle method (Strickland \& Parsons 1972). The advantage of using oxygen is that respiration can be measured in the dark, allowing determination of gross photosynthetic rates. Another common technique uses radioactive ${ }^{14} \mathrm{C}$ as a tracer (Steemann-Nielsen 1952). The advantage of the ${ }^{14} \mathrm{C}$ technique is extreme sensitivity and the ability to measure much lower productivity than is possible using the light and dark bottle oxygen method. This sensitivity allows shorter incubations and studies of oligotrophic regions where the oxygen method may not yield reliable results (Sakshaug et al. 1997). The main disadvantage of the ${ }^{14} \mathrm{C}$ technique is the lack of measurement and estimation of gross or net photosynthesis. Long incubations with ${ }^{14} \mathrm{C}$ should approximate net primary production. Short incubations should approximate gross primary production, because the ${ }^{14} \mathrm{C}$ fixed into organic matter will have less time to be released by respiration (Dring \& Jewson 1982).

A common disadvantage shared by the oxygen and ${ }^{14} \mathrm{C}$ methods is that they require that the samples be incubated in a container, creating artifacts. For exam- 
ple, phytoplankton and bacteria can grow on the walls of the container creating an artificial growth condition (Carpenter \& Lively 1980, Peterson 1980). Another problem is that the containers and reagents must be kept clean to prevent the risk of contamination by metals that affect growth rates (Fitzwater et al. 1982). Another important limitation of either technique is that the required incubations are time consuming, and this limits the practical sampling rate.

Variable fluorescence has been used to probe the dynamics of photosystem II (PSII), as well as to derive a number of diagnostic parameters, such as the $F_{\mathrm{v}} / F_{\mathrm{m}}$ ratio. In this ratio, $F_{\mathrm{v}}$ stands for variable fluorescence and $F_{\mathrm{m}}$ is maximum fluorescence. The $F_{\mathrm{v}} / F_{\mathrm{m}}$ ratio has been considered a proxy for the maximum quantum yield of photosynthesis, and has been used as an indicator of nutrient stress (Kolber et al. 1990, Falkowski \& Raven 1997, Parkhill et al. 2001, Sakshaug et al. 1997). Examples of how this capability has been applied to oceanographic research include studying the iron limitation hypothesis (Greene et al. 1991, Kolber et al. 1994, Behrenfeld et al. 1996, Behrenfeld \& Kolber 1999, Suzuki et al. 2002) and zooxanthellae in corals (Gorbunov et al. 2000).

Common techniques for measuring variable fluorescence include pump and probe fluorescence (PPF), fast repetition rate fluorescence (FRRF), and pulse amplitude modulation (PAM). These differ in how excitation energy is delivered to stimulate a fluorescence response. In oceanographic phytoplankton research the FRRF has become the dominant technique in recent years (Suggett et al. 2003). A key advantage of the FRRF is a more rapid assessment of photosynthetic parameters than with other variable fluorescence techniques (Kolber et al. 1998), which is useful when trying to make in situ oceanographic measurements.

The capability of the FRRF to rapidly assess photosynthetic rates is also an advantage when compared with other non-fluorescence-based techniques. The FRRF technique does not require time-consuming incubations or costly reagents. It allows productivity to be measured in situ without the risk of artifacts introduced by incubating in a container. It also allows much more detailed profiling of productivity in the water column, because of its fast sampling rate.

Since PSII is the step where oxygen evolution occurs, there is a relationship between variable fluorescence and oxygen production. Carbon fixation does not take place in PSII; however, a fraction of the electrons passed from PSII to photosystem I (PSI) are used for this purpose. For this reason carbon fixation will be indirectly related to PSII fluorescence by the photosynthetic quotient. Kolber \& Falkowski (1993) developed a model based on the relationship between PSII fluorescence and electron transport to allow the measurement of primary production using variable fluorescence. They applied the model using the PPF technique, and compared it with measurements of ${ }^{14} \mathrm{C}$ uptake. The productivity estimates from the PPF were linearly related to estimates from the ${ }^{14} \mathrm{C}$ techniques, with a regression slope of slope of 1.06 and an $\mathrm{r}^{2}$ of 0.86 , indicating an almost 1 to 1 relationship. Suggett et al. (2001) applied the model to data obtained using the FRRF technique. They found a lower $\mathrm{r}^{2}$ of 0.59 with a slope of 2.166 for the regression line between ${ }^{14} \mathrm{C}$ and the FRRF. This slope was quite different from what Kolber \& Falkowski had observed. Boyd et al. (1997) compared the individual photosynthetic parameters derived by ${ }^{14} \mathrm{C}$ and the PPF techniques, and found that the parameters were correlated, but the absolute values obtained frequently differed. They attributed this in part to the spectral difference between the light source used in the ${ }^{14} \mathrm{C}$ measurements and the in situ light field present during the PPF measurements. Similar measurements of primary production have also been performed in freshwater using variable fluorescence techniques such as the PAM. Suggett et al. (2003) reported that estimates of photosynthetic rates determined by FRRF or PAM fluorescence techniques may differ in magnitude from ${ }^{14} \mathrm{C}$ and oxygen measurements by factors ranging from 0.25 to 15 .

The fact that these studies found correlations between the fluorescence and ${ }^{14} \mathrm{C}$, but did not find a consistent relationship raises questions about the reliability and interpretation of primary production estimates derived from variable fluorescence. To assess the variability in this technique it is necessary to compare ${ }^{14} \mathrm{C}$ and variable fluorescence for a range of phytoplankton samples. The goal of this study was to perform such comparisons in order to evaluate the meaning of variable fluorescence-based measurements of primary productivity.

\section{MATERIALS AND METHODS}

FRRF measurements. Variable fluorescence data were collected using a Chelsea Technologies Group (CTG) Fast ${ }^{\text {Tracka }}$ FRRF. Although a CTG instrument was used in this research, this paper should not be considered a National Marine Fisheries Service endorsement of a specific manufacturer. The FRRF was provided by the U.S. National Marine Fisheries Service's Bay Window monitoring program based in Narragansett, RI (Berman \& Sherman 2001). The data acquisition protocol consisted of 100 excitation flashes, with a flash duration of $1.94 \mu \mathrm{s}$ and an inter-flash delay of $3.6 \mu \mathrm{s}$, and 20 relaxation flashes, with a flash duration of $1.94 \mu \mathrm{s}$ and an inter-flash delay of $99.6 \mu \mathrm{s}$. Our protocol differed from Chelsea's standard factory 
settings because the default protocol did not achieve full saturation of quinone-a $\left(Q_{a}\right)$ for all samples during the excitation sequence and the relaxation sequence was not allowing sufficient re-oxidation of $Q_{a}$.

This FRRFs gain constants were altered from Chelsea's standard values, because it was used primarily in Narragansett Bay, where the natural concentrations of phytoplankton were routinely high enough to cause the instrument to saturate at the least sensitive gain normally available. For this reason the instrument was desensitized and recalibrated by Chelsea to allow it to handle the higher phytoplankton concentrations encountered in this study. All of the phytoplankton concentrations studied here were high enough to be read on this desensitized instrument's 3 least-sensitive gain settings.

Data from the FRRF were processed using the postprocessing software provided by Chelsea Instruments. This software derived photosynthetic parameters from the FRRF response curve, an example of which is illustrated in Fig. 1. The parameters derived included the maximum fluorescence $\left(F_{\mathrm{m}}\right)$, the initial fluorescence when all reaction centers were open $\left(F_{0}\right)$, the reoxidation rate of $\mathrm{Q}_{\mathrm{a}}\left(\tau_{\mathrm{q}}\right)$, the functional absorption cross-section of PSII $\left(\sigma_{\mathrm{PSII}}\right)$, as well as the initial fluorescence $\left(F^{\prime}\right)$ and maximum fluorescence $\left(F_{\mathrm{m}}{ }^{\prime}\right)$ under ambient light.

FRRF primary productivity model. FRRF measurements of quantum yield were calculated according to the following equation using the model developed by Kolber \& Falkowski (1993):

$$
P_{\mathrm{c}}^{\mathrm{B}}=I \sigma_{\mathrm{PSII}} q_{\mathrm{p}} \phi_{\mathrm{e}} f \eta_{\mathrm{PSII}} / \mathrm{PQ}
$$

$P_{\mathrm{c}}^{\mathrm{B}}$ is the rate of carbon fixation normalized to chlorophyll $a(\mathrm{chl} a)$ at irradiance $I\left(\mu \mathrm{mol}\right.$ quanta $\mathrm{m}^{-2}$ $\mathrm{s}^{-1}$ ). PQ is the photosynthetic quotient, and a typical value of $1.2 \mathrm{~mol}$ oxygen $\mathrm{mol}^{-1}$ carbon was assumed. The functional absorption cross section of PSII is $\sigma_{\mathrm{PSII}}$ $\left(\AA^{2}\right.$ quanta $\left.^{-1}\right)$. A conversion factor of 0.291409 was applied to the results of Eq. (1) to give the final productivity results (in $\mathrm{mg} \mathrm{C} \mathrm{mg}^{-1} \mathrm{chl} a \mathrm{~h}^{-1}$. This factor includes conversions for micromoles quanta to moles quanta, moles chl a to milligrams chl $a$, quanta to moles quanta, square ångströms to square meters, seconds to hours, and moles $\mathrm{C}$ to milligrams $\mathrm{C}$.

The $\eta_{\text {PSII }}$ term in Eq. (1) is the ratio of PSII reaction centers to chl a (mol electrons $\mathrm{mol}^{-1} \mathrm{chl} a$ ). This term cannot be measured by the FRRF (Kolber et al. 1998, Suggett et al. 2001), nor can it easily be determined by other means. This limitation also applied to the PPF technique used by Kolber \& Falkowski (1993). Their solution was to estimate the value of $\eta_{\text {PSII }}$ by assuming a typical value for the western North Atlantic of $0.002 \mathrm{~mol}$ electrons $\mathrm{mol}^{-1} \mathrm{chl}$ a (Kolber \& Falkowski 1993). The use of a constant value for $\eta_{\text {PSII }}$ introduces a potential source of error to the calculations of produc-

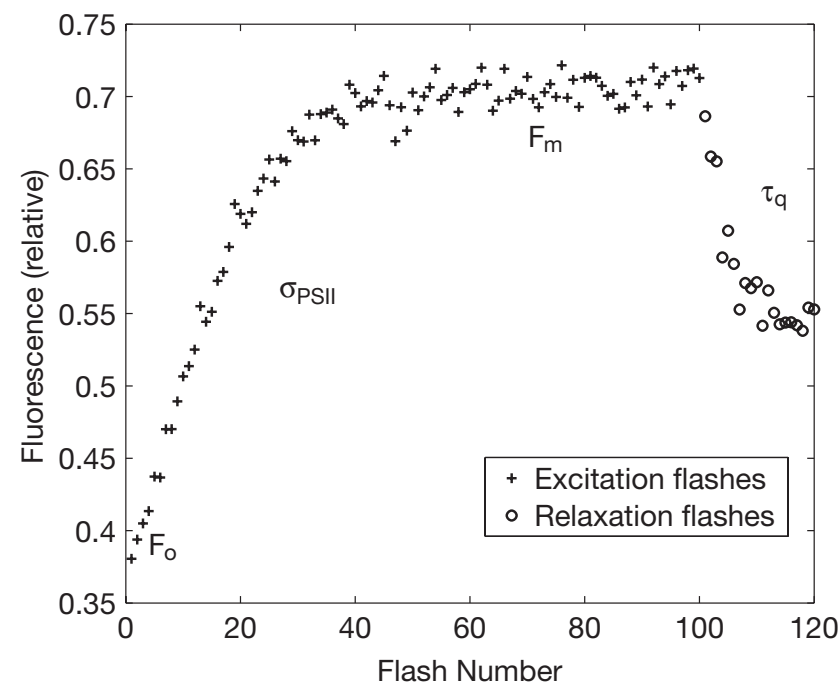

Fig. 1. Example of a typical fast repetition rate fluorescence (FRRF) acquisition plot, with 100 excitation flashes and 20 relaxation flashes. The initial value of the curve represents $F_{0}$, the peak indicates $F_{\mathrm{m}}, \sigma_{\mathrm{PSII}}$ is derived by fitting a model to the excitation flash response, and $\tau_{\mathrm{q}}$ is derived by fitting a model to the relaxation flash response

tivity, since Kolber \& Falkowski (1993) suggest this value may vary by a factor of 3 in the oceans.

The $q_{\mathrm{p}}$ term in Eq. (1) describes photochemical quenching, and can be expanded to:

$$
q_{\mathrm{p}}=\left(F_{\mathrm{m}}{ }^{\prime}-F^{\prime}\right) /\left(F_{\mathrm{m}}-F_{0}\right)
$$

Eq. (2) is modified from the equation for $q_{\mathrm{p}}$ used by Kolber \& Falkowski (1993). In the original form of the equation, the $F_{\mathrm{m}}$ in the denominator of Eq. (2) was $F_{\mathrm{m}}$ '. It has been changed to $F_{\mathrm{m}}$ to accommodate operational considerations with the FRRF when it is deployed in situ in a profiling mode. $F_{0}$ and $F_{\mathrm{m}}{ }^{\prime}$ are measured in situ in separate chambers, which have different optical characteristics and excitation light sources. The FRRF has a 'light chamber' that is not enclosed and measures samples exposed to ambient light, as well as a 'dark chamber' that is enclosed and shielded from ambient light. Furthermore, the light and dark chambers do not fire simultaneously, and will not be measuring exactly the same sample of phytoplankton. The result of $F_{\mathrm{m}}{ }^{\prime}-$ $F_{0}$ is very sensitive to small offsets between the 2 chambers, and this results in large errors in $q_{\mathrm{p}} . F_{\mathrm{m}}$ closely approximates $F_{\mathrm{m}}{ }^{\prime}$, and is measured in the dark chamber at the same time as $F_{0}$. For this reason, $F_{\mathrm{m}}$ was substituted for $F_{\mathrm{m}}$ ' in the denominator of Eq. (2) to deal with the chamber offset problem.

The $\phi_{\mathrm{e}}\left(\mathrm{mol} \mathrm{O}_{2} \mathrm{~mol}^{-1}\right.$ quanta) term in Eq. (1) describes the quantum yield of PSII accounting for thermal losses and electron cycling in PSII. Calculation of this term depends on the irradiance. If the rate of photosynthetic electron transport in PSII is less than the rate at 
which electrons can be transferred to PSI, the value of this term is fixed at 0.25 . At higher irradiances, when the electron transport rates in PSII exceed the rate at which they may be transferred to PSI, the system becomes less efficient. Eq. (4), used by Kolber \& Falkowski (1993) to account for reduced efficiency, requires knowledge of the whole chain turnover time of PSII, designated by $\tau_{\mathrm{p}}$. The value of $\phi_{\mathrm{e}}$ is calculated according to either Eq. (3) or Eq. (4) (shown below), depending on conditions:

$$
\begin{gathered}
\phi_{\mathrm{e}}=0.25 \text {, where }\left(I \sigma_{\mathrm{PSII}} q_{\mathrm{p}}\right) \quad\left(1 / \tau_{\mathrm{p}}\right) \\
\phi_{\mathrm{e}}=0.25 /\left(I \sigma_{\mathrm{PSII}} q_{\mathrm{P}} \tau_{\mathrm{p}}\right) \text {, where }\left(I \sigma_{\mathrm{PSII}} q_{\mathrm{p}}\right)>\left(1 / \tau_{\mathrm{p}}\right)
\end{gathered}
$$

In our study Eq. (4) was used at all times, because estimating $\tau_{\mathrm{p}}$ by FRRF was found to be problematic. The FRRF is only capable of measuring the turnover time of $\mathrm{Q}_{\mathrm{a}}\left(\tau_{\mathrm{q}}\right)$ directly and not $\tau_{\mathrm{p}}$. To reliably assess $\tau_{\mathrm{p}}$ requires numerous measurements over a range of irradiance (Kolber \& Falkowski 1993). Since this may not always be practical, particularly when performing in situ measurements, the static value of 0.25 was used for $\phi_{\mathrm{e}}$ in all cases.

The theoretical maximum photosynthetic energy conversion efficiency, $f$, is given by Eq. (5) such that:

$$
f=(1 / 0.65)\left[\left(F_{\mathrm{m}}-F_{0}\right) / F_{\mathrm{m}}\right]
$$

Another simplified model for estimating productivity by FRRF was created by Smyth et al. (2004):

$$
P=1.87 \times 10^{-4}\left(F_{\mathrm{m}}{ }^{\prime}-F^{\prime}\right) / F_{\mathrm{m}}{ }^{\prime} \sigma_{\mathrm{PSII}}(\max ) I[\mathrm{chl} a]
$$

The Kolber \& Falkowski (1993) model (Eq. 1) and the Smyth et al. (2004) model (Eq. 6) were both used to calculate primary productivity for all FRRF data. Eq. (6) assumes the same values for $\eta_{\text {PSII }}$ and PQ as were used with Eq. (1). The Kolber \& Falkowski (1993) model was used in all of the FRRF comparisons with the ${ }^{14} \mathrm{C}$ method.

Because the Kolber \& Falkowski model given in Eq. (1) provides productivity normalized to chl $a_{\text {, }}$ whereas the ${ }^{14} \mathrm{C}$ method and the Smyth et al. (2004) model both provide bulk productivity, it was necessary to multiply the results of Eq. (1) by the chl a concentration to obtain the bulk productivity for comparisons between the different methods. The chl a concentrations were estimated using the FRRF itself. The FRRF $F_{\mathrm{m}}$ term was calibrated to units of chl $a$ and was then used in the same way an oceanographic profiling fluorometer is used to estimate chl a concentration from in vivo fluorescence.

Laboratory productivity measurements. Water samples from Massachusetts Bay, collected as part of a Massachusetts Water Resources Authority monitoring program, were analyzed using the ${ }^{14} \mathrm{C}$ uptake and FRRF techniques. Samples were collected from 3 stations (Fig. 2) during several months of the year 2000 and were returned to the University of Rhode Island's Marine Ecosystems Research Laboratory for analysis the same day (Table 1).

The ${ }^{14} \mathrm{C}$ method employed was adapted from Strickland \& Parsons (1972), and is described in detail in Oviatt et al. (2002). For each phytoplankton sample, 16 sub-samples of $5 \mathrm{ml}$ were spiked with sodium carbonate marked with ${ }^{14} \mathrm{C}$ and incubated for $1 \mathrm{~h}$ at light intensities ranging from about 5 to $2000 \mu \mathrm{mol}$ quanta $\mathrm{m}^{-2} \mathrm{~s}^{-1}$. The ${ }^{14} \mathrm{C}$ activity of the samples was determined by liquid scintillation spectrometry. The short $1 \mathrm{~h}$ incubation means that the results should approximate gross primary production.

The hourly primary production at each light intensity was then determined using Eq. (7) such that:

$$
P=\left[1.05\left(A_{I}-A_{\mathrm{d}}\right) C\right] /(S t)
$$

$A_{I}$ is the ${ }^{14} \mathrm{C}$ activity of a sample incubated at irradiance $I$ following the incubation, $A_{\mathrm{d}}$ is the ${ }^{14} \mathrm{C}$ activity of the sample incubated in the dark, $C$ is the dissolved inorganic carbon concentration measured for a separate sub-sample not inoculated with ${ }^{14} \mathrm{C}, S$ is the stock ${ }^{14} \mathrm{C}$ activity added at the beginning of the incubation, and $t$ is the length of incubation. The 1.05 in the equation is to correct for the difference between the uptake rate of ${ }^{14} \mathrm{C}$ and ${ }^{12} \mathrm{C}$ during photosynthesis.

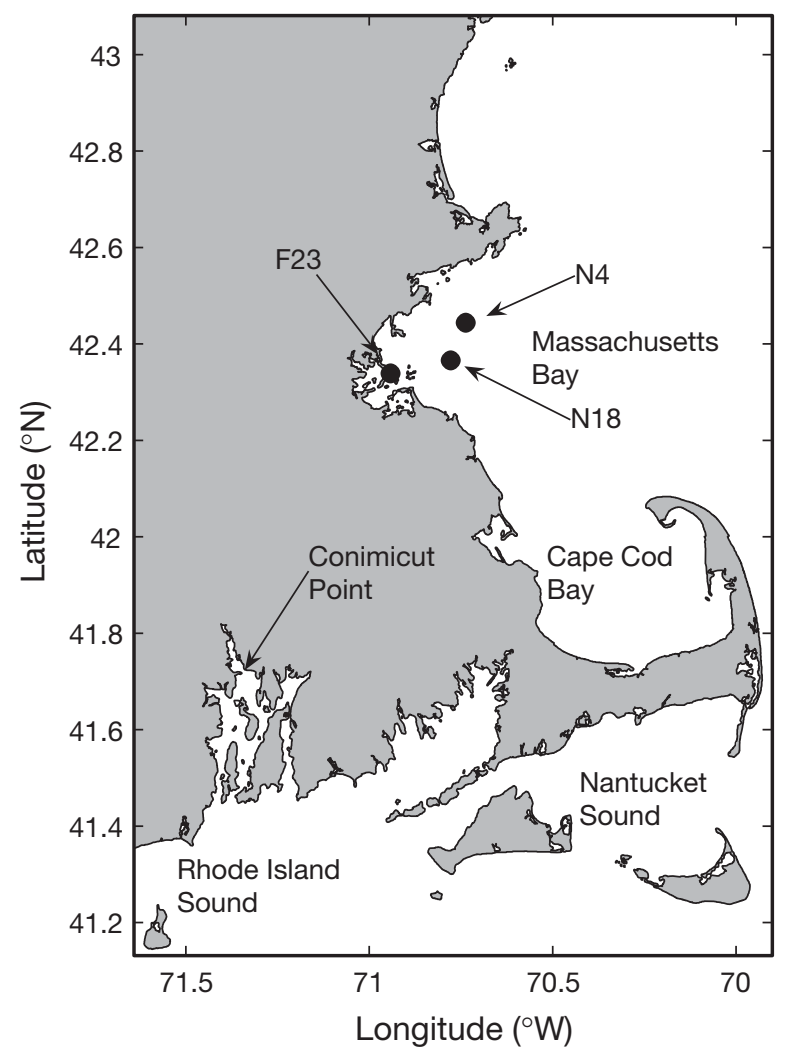

Fig. 2. Sampling stations in Massachusetts Bay (F23, N4 and N18) and in Narragansett Bay (Conimicut Point) 
Table 1. Results of linear regressions comparing $\log _{10}$-transformed ${ }^{14} \mathrm{C}$ and FRRF-based productivity estimates for 38 plankton samples from Massachusetts Bay, each measured at 13 light intensities, are summarized. The depths are relative and are given by $\mathrm{S}$ (surface), MS (between mid-depth and surface), $M$ (mid-depth), MB (between the bottom and mid-depth), and B (bottom)

\begin{tabular}{|c|c|c|c|c|c|}
\hline Date & Station & Depth & Slope & Intercept & $r^{2}$ \\
\hline \multirow[t]{8}{*}{27 Feb 2000} & N18 & $\mathrm{S}$ & 0.80 & -0.31 & 0.54 \\
\hline & N18 & MS & 1.04 & -0.36 & 0.39 \\
\hline & N18 & $\mathrm{M}$ & 0.87 & -0.49 & 0.52 \\
\hline & F23 & $\mathrm{S}$ & 1.42 & -0.55 & 0.76 \\
\hline & F23 & MS & 1.05 & -0.20 & 0.89 \\
\hline & F23 & $\mathrm{M}$ & 1.14 & -0.44 & 0.74 \\
\hline & F23 & MB & 1.14 & -0.43 & 0.35 \\
\hline & F23 & B & 0.94 & -0.13 & 0.93 \\
\hline \multirow[t]{9}{*}{14 Mar 2000} & N4 & $\mathrm{S}$ & 0.95 & -0.64 & 0.93 \\
\hline & N4 & MS & 0.90 & -0.44 & 0.82 \\
\hline & N4 & $\mathrm{M}$ & 1.18 & -0.67 & 0.85 \\
\hline & N4 & B & 1.07 & -0.48 & 0.76 \\
\hline & N18 & $\mathrm{S}$ & 0.94 & -0.65 & 0.82 \\
\hline & N18 & MS & 1.03 & -0.62 & 0.95 \\
\hline & N18 & $\mathrm{M}$ & 0.89 & -0.44 & 0.88 \\
\hline & N18 & MB & 0.83 & -0.33 & 0.92 \\
\hline & N18 & B & 0.95 & -0.50 & 0.97 \\
\hline 1 Apr 2000 & N4 & MB & 0.65 & -0.12 & 0.62 \\
\hline 1 May 2000 & N4 & $\mathrm{S}$ & 1.09 & -0.58 & 0.76 \\
\hline \multirow[t]{3}{*}{17 May 2000} & N4 & M & 0.71 & -0.37 & 0.19 \\
\hline & N18 & $\mathrm{S}$ & 0.72 & -0.12 & 0.77 \\
\hline & N18 & MS & 0.67 & -0.08 & 0.83 \\
\hline \multirow[t]{6}{*}{24 Oct 2000} & N4 & $\mathrm{S}$ & 1.03 & -0.43 & 0.95 \\
\hline & N4 & MS & 0.94 & -0.31 & 0.99 \\
\hline & N4 & $\mathrm{M}$ & 0.99 & -0.46 & 0.91 \\
\hline & N18 & $\mathrm{S}$ & 0.93 & -0.27 & 0.96 \\
\hline & N18 & MS & 1.06 & -0.35 & 0.95 \\
\hline & N18 & $\mathrm{M}$ & 0.84 & -0.22 & 0.88 \\
\hline \multirow[t]{10}{*}{29 Nov 2000} & N18 & $\mathrm{S}$ & 1.02 & -0.34 & 0.55 \\
\hline & N18 & MS & 0.84 & -0.32 & 0.92 \\
\hline & N18 & $\mathrm{M}$ & 0.98 & -0.14 & 0.96 \\
\hline & N18 & MB & 1.01 & -0.23 & 0.78 \\
\hline & N18 & B & 0.81 & -0.38 & 0.91 \\
\hline & N4 & $\mathrm{S}$ & 1.05 & -0.32 & 0.71 \\
\hline & N4 & MS & 1.01 & -0.34 & 0.75 \\
\hline & N4 & $\mathrm{M}$ & 0.90 & -0.25 & 0.71 \\
\hline & N4 & MB & 0.85 & -0.18 & 0.66 \\
\hline & N4 & B & 0.86 & -0.31 & 0.81 \\
\hline
\end{tabular}

Photosynthesis versus irradiance curves were generated from the series of hourly productivity measurements at each light intensity by fitting the results to a photosynthesis model with photoinhibition (Eq. 8) developed by Platt et al. (1980):

$$
P=P_{\mathrm{sb}}\left[1-\mathrm{e}^{-(\alpha I) /\left(P_{\mathrm{sb}}\right)}\right] \mathrm{e}^{-(\beta I) /\left(P_{\mathrm{sb}}\right)}
$$

$P$ is the productivity $\left(\mathrm{g} \mathrm{C} \mathrm{h}^{-1} \mathrm{~m}^{-3}\right), P_{\mathrm{sb}}$ is theoretical maximum productivity without photoinhibition $\left(\mathrm{mg} \mathrm{C} \mathrm{h} \mathrm{h}^{-1}\right.$ $\mathrm{m}^{-3}$ ), $I$ is the irradiance ( $\mu \mathrm{mol}$ quanta $\left.\mathrm{m}^{-2} \mathrm{~s}^{-1}\right), \alpha$ is the initial slope of the curve ( $\mathrm{mg} \mathrm{C} \mu \mathrm{mol}$ quanta ${ }^{-1} \mathrm{~m}^{-1}$ ), and $\beta$ is the photoinhibition term ( $\mathrm{mg} \mathrm{C} \mu \mathrm{mol}$ quanta ${ }^{-1} \mathrm{~m}^{-1}$ ).

Laboratory FRRF measurements were made on a $200 \mathrm{ml}$ sub-sample (not spiked with ${ }^{14} \mathrm{C}$ ) held in a non- fluorescent glass cuvette using our standard protocol described earlier. Variable fluorescence was measured at 12 light intensities ranging from 0 to $2100 \mu \mathrm{mol}$ quanta $\mathrm{m}^{-2} \mathrm{~s}^{-1}$ and in the dark in a temperaturecontrolled room. At each light intensity, 6 flash sequences were averaged to reduce sampling noise. Samples were read in order of increasing irradiance, beginning with the dark readings, and were allowed to remain at each light intensity for approximately $6 \mathrm{~s}$. Following light exposure, 10 successive dark readings were taken at $6 \mathrm{~s}$ intervals to assess the rate of dark adaptation of the cells. A magnetic stirrer gently mixed all samples to prevent the phytoplankton from settling during the FRRF measurements.

Primary productivity measured by the 2 different techniques was compared using a reduced major axis functional regression. Linear regressions were based on $\log _{10}$-transformed productivity estimates. This transformation was required to generate a regression line that equitably weighted the observations over the large dynamic range encompassed by the data.

In situ productivity measurements. Vertical profiles of FRRF and PAR (photosynthetically active radiation) measurements were made at Conimicut Point in Narragansett Bay (Fig. 2) during monthly cruises in 2001. The PAR measurements were collected using the FRRFs attached hemispherical PAR sensor. Water samples were taken from 3 depths: $1 \mathrm{~m}$, the depth of the pycnocline, and below the pycnocline. These samples were returned to the laboratory and were incubated using the ${ }^{14} \mathrm{C}$ method described earlier.

\section{RESULTS}

\section{Massachusetts Bay primary productivity}

Linear regressions of $\log _{10}$-transformed estimates of primary productivity from the FRRF and ${ }^{14} \mathrm{C}$ methods generally yielded high $\mathrm{r}^{2}$ values (Table 1 ). We chose to use linear regressions because this approach fit the majority of our samples well. Out of 38 samples, 13 produced $r^{2}$ values $>0.9$. In a few samples with noisy FRRF data, the techniques yielded a low $r^{2}$, and the FRRF productivity model results showed a weak relationship to irradiance. The cause of the noise in the FRRF data in these few cases was not determined. It may have been an electronic fault, or a problem resulting from the specific phytoplankton samples. An example of this was evident in results from the N18 station samples on 27 February 2000, where the FRRF data processing software had difficulty calculating basic photosynthetic parameters such as $F_{\mathrm{m}}$ even when measured in the dark. 


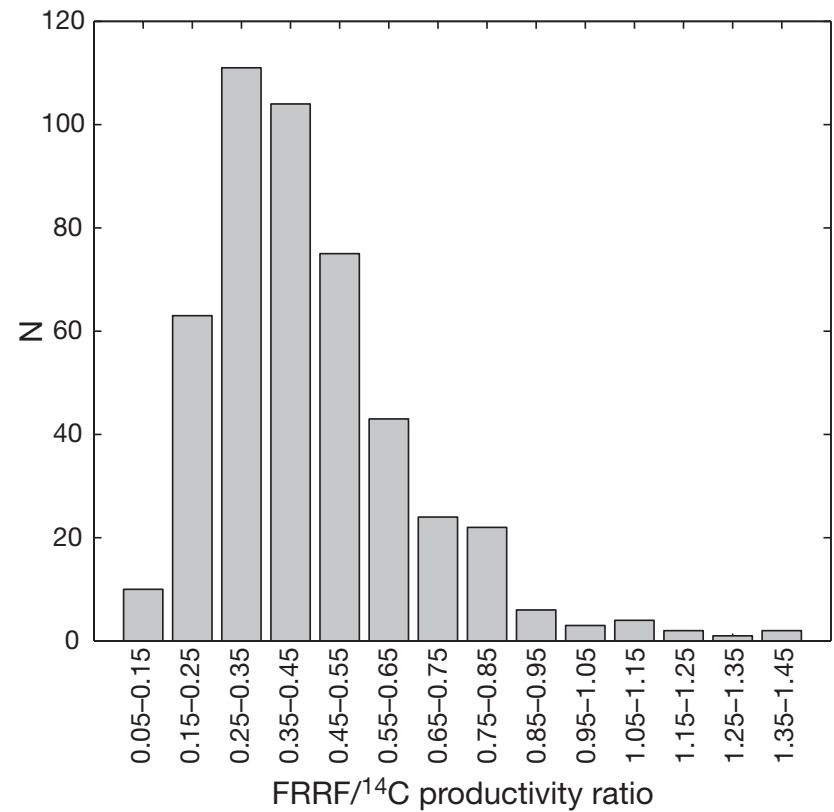

Fig. 3. Frequency histogram of the ratio of FRRF- to ${ }^{14} \mathrm{C}$ based productivity measurements. $\mathrm{N}=$ number of samples

The ratio of individual measurements of productivity made by the FRRF to the ${ }^{14} \mathrm{C}$ method ranged between 0.07 and 1.44 (Fig. 3). The most common ratio was between 0.25 and 0.35 . The median ratio was 0.39 , and the mean was 0.43 . The ratio exceeded 1 in only 11 of the 470 measurements. These results indicate that the FRRF typically underestimated primary productivity relative to ${ }^{14} \mathrm{C}$ if no correction was applied.

Although there was some variability in the regression slopes obtained for samples from different depths at an individual station, this variability was usually smaller than the variability between stations and dates (Table 1). An example of one of the better-correlated samples, taken at Stn N4 on 24 October 2000, demonstrated that a tight linear fit can be achieved between the FRRF and ${ }^{14} \mathrm{C}$ (Fig. 4). This sample also falls into the range of the most commonly observed regression slopes.

A regression of all FRRF- and ${ }^{14} \mathrm{C}$-based productivity estimates from Massachusetts Bay was performed to compare the techniques across a wide range of seasons and phytoplankton communities (Fig. 5). The slope for all of the $\log _{10}$-transformed productivity data was 0.86 , with an $\mathrm{r}^{2}$ of 0.81 . This indicated that even across a wide range of conditions there is a clear general relationship between the FRRF and ${ }^{14} \mathrm{C}$ technique.

\section{Narragansett Bay primary productivity}

Experiments using the FRRF deployed in situ in Narragansett Bay yielded an excellent linear relationship

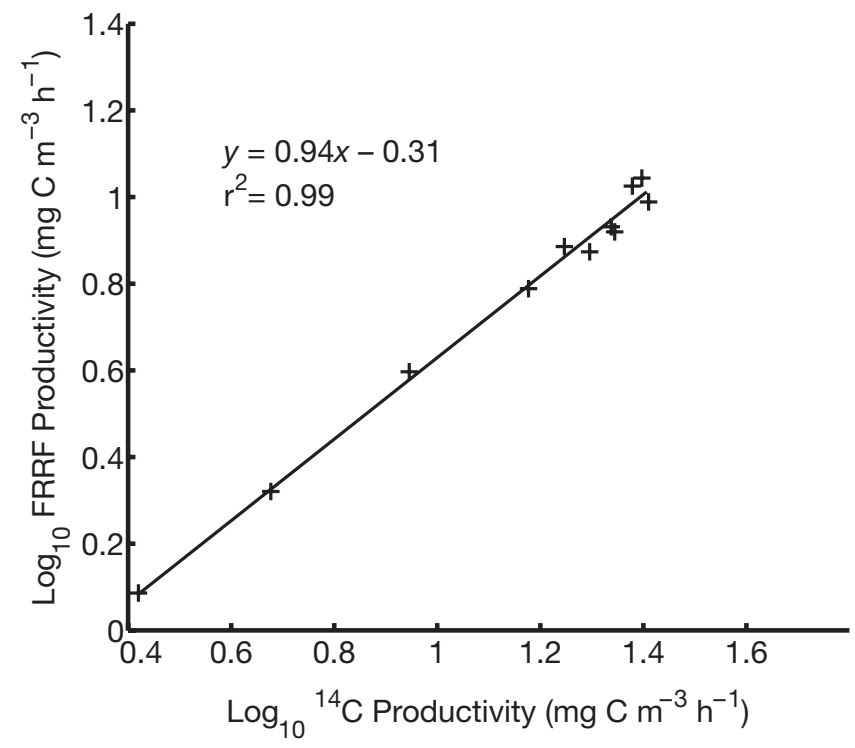

Fig. 4. Comparison of an individual sample between ${ }^{14} \mathrm{C}$ - and FRRF-estimated productivity can yield a very tight linear fit, as was illustrated in this case. This sample was taken from Massachusetts Bay Stn N4 on 24 October 2000

with the ${ }^{14} \mathrm{C}$ method, with slopes slightly higher than was typical for Massachusetts Bay (Fig. 6). Measurements taken at Conimicut Point in the Providence River on 16 August 2001 (Fig. 6) indicated a slope of 1.09 for the relationship between $\log _{10}$-transformed ${ }^{14} \mathrm{C}$ - and FRRF-based productivity data. Similar measurements taken on 14 September 2001 (Fig. 6) yielded a lower slope of 0.9 , with an $\mathrm{r}^{2}$ of 1 . On 9 November 2001 at the same location, the slope was 1.07 (Fig. 6).

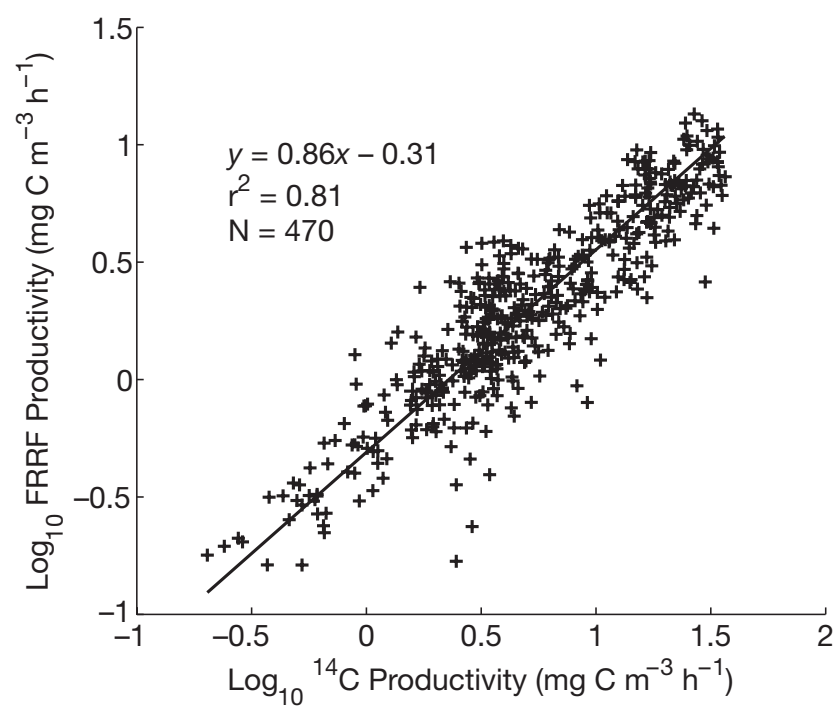

Fig. 5. Type II linear regression between the $\log _{10}$-transformed FRRF and ${ }^{14} \mathrm{C}$ productivity estimates for all data from Massachusetts Bay. An individual point represents a single measurement at a single light intensity for 1 sample 
August 16, 2001

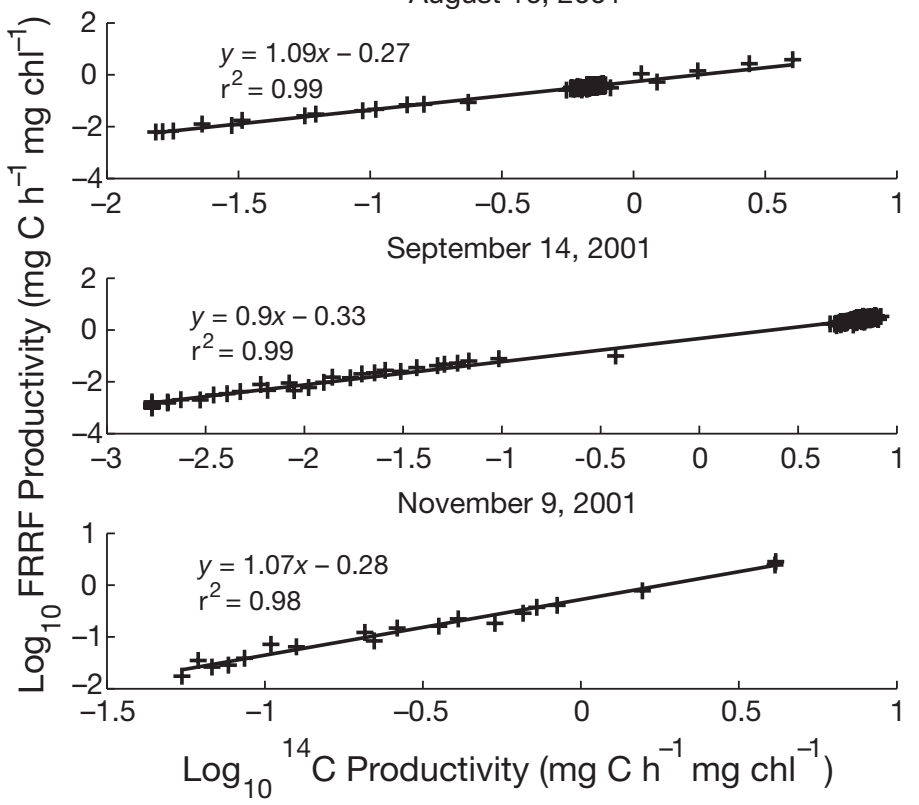

Fig. 6. FRRF-estimated instantaneous in situ productivity was determined from a short (several minutes) vertical cast at Conimicut Point in Narragansett Bay on 16 August, 14 September, and 9 November 2001. Samples were also taken for ${ }^{14} \mathrm{C}$ analysis from 3 depths. A Type II linear regression was performed on the $\log _{10}$-transformed productivity estimates from both the ${ }^{14} \mathrm{C}$ and FRRF techniques

All of these values fell within the range of slopes calculated for the Massachusetts Bay data. In all cases the $\mathrm{r}^{2}$ was 0.98 or higher. These $r^{2}$ values were higher than was typical with the Massachusetts Bay laboratory experiments (Table 1).

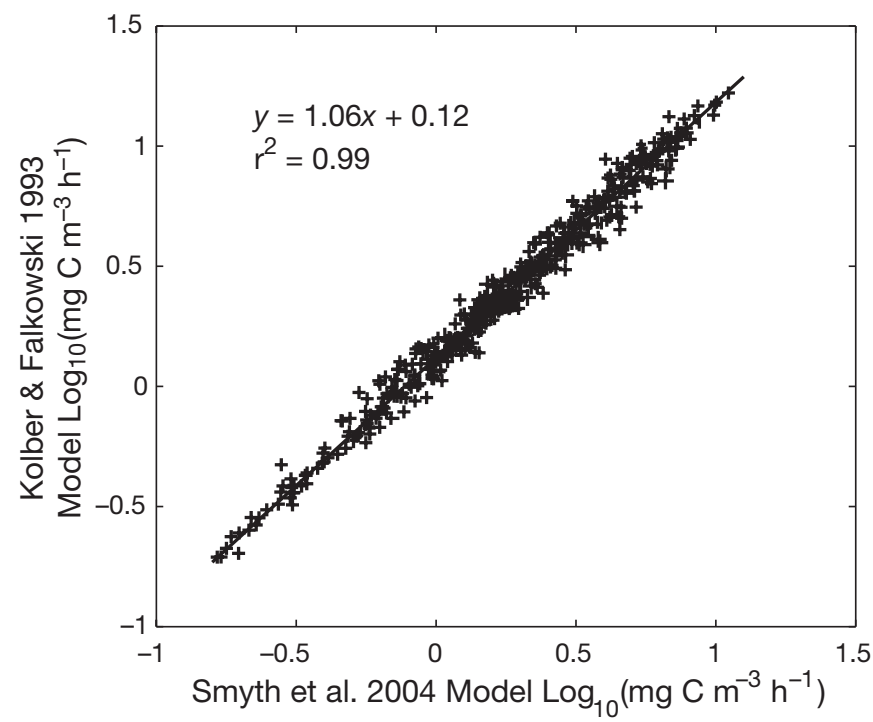

Fig. 7. Type II linear regression comparing the Kolber \& Falkowski (1993) and Smyth et al. (2004) models for all data from Massachusetts Bay

\section{FRRF productivity model comparison}

A comparison of the log-transformed results of the Kolber \& Falkowski (1993) and Smyth et al. (2004) models when applied to the same FRRF data showed an extremely coherent linear relationship (Fig. 7), with an $r^{2}$ of 0.99 . The slope of 1.06 indicated that the Smyth et al. (2004) model produced slightly lower estimates of productivity than the Kolber \& Falkowski (1993) model. The tight relationship between the 2 techniques indicates that both models perform similarly and that both are viable choices when performing FRRF estimates of productivity. The difference in the magnitude of the estimates produced by both models appears consistent and could easily be adjusted.

\section{DISCUSSION}

\section{FRRF and ${ }^{14} \mathrm{C}$ comparisons}

The FRRF yielded strong linear relationships with measurements of ${ }^{14} \mathrm{C}$ uptake in individual comparisons for data collected in both Massachusetts and Narragansett Bay. The most common ratio between ${ }^{14} \mathrm{C}$ and the FRRF measurements was between 0.25 and 0.35 (Fig. 3), with a clear central tendency in the distribution suggesting that the FRRF can provide a reliable technique for assessing productivity. However, since the FRRF has been shown here to underestimate production relative to the ${ }^{14} \mathrm{C}$ technique, the magnitude of estimates would differ from estimates produced using other techniques unless a correction was applied.

The observations made in this study were consistent with those of Suggett et al. (2003), who reported that the relationship between traditional measurements of primary productivity and fluorescence-based measurements varied from a factor of 0.25 to 15 . The ratios between the FRRF and ${ }^{14} \mathrm{C}$ techniques presented here for both Narragansett Bay and Massachusetts Bay experiments fell between 0.07 and 1.44, which is a much narrower range. The results obtained by Kolber \& Falkowski (1993) and Suggett et al. (2001) comparing variable florescence and ${ }^{14} \mathrm{C}$ uptake measurements of productivity fall within the range of the relationships presented in this paper.

The Kolber \& Falkowski (1993) model includes 2 parameters the FRRF does not measure; this explains part of the observed variability and the need for calibration. These parameters are the photosynthetic quotient and the ratio of $\mathrm{chl}$ a to PSII reaction centers $\left(h_{\text {PSII }}\right)$. The value of $h_{\text {PSII }}$ may be determined in the laboratory, but no practical technique currently exists for measuring it in situ (Kolber \& Falkowski 1993, Suggett et al. 2001). However, if the FRRF results were cor- 
rected empirically against chemical measurements, it would not matter if incorrect values were assumed for either of the 2 terms mentioned.

An additional source of error in FRRF measurements that has not been directly addressed is the assumption that the $F_{\mathrm{v}} / F_{\mathrm{m}}$ ratio, which is used in the Kolber \& Falkowski model, is an indicator of the maximum quantum yield of PSII. This term is often used to diagnose nutrient limitation. However, Parkhill et al. (2001) found this was not a robust diagnostic indicator in culture studies. In steady-state nutrient-limiting conditions, cells adapted and exhibited a high $F_{\mathrm{v}} / F_{\mathrm{m}}$ ratio while growth remained low. The $F_{\mathrm{v}} / F_{\mathrm{m}}$ was only low when cells were exposed to short-term nutrient starvation. Over longer periods when cells had an opportunity to acclimate, $F_{\mathrm{v}} / F_{\mathrm{m}}$ returned to higher values, but growth rates and actual quantum yield remained low. This would cause the Kolber \& Falkowski (1993) model to fail to detect decreases in growth rates in cells acclimated to low nutrient concentrations. Errors introduced by this problem would be corrected by calibrating the FRRF against an incubation technique such as ${ }^{14} \mathrm{C}$ or oxygen in the field.

Another problem related to the measurement of the $F_{\mathrm{v}} / F_{\mathrm{m}}$ ratio is the presence of phaeophytin. Phaeophytin is produced when chl $a$ is digested by grazers, such as zooplankton. If the quantity of phaeophytin accounts for $>30 \%$ of the total pigment present in a sample, it will lead to a reduction in the measured $F_{\mathrm{v}} / F_{\mathrm{m}}$ ratio, and an underestimation of primary productivity (Fuchs et al. 2002). If the phaeophytin concentration is known, it is possible to apply a correction term to the data (Fuchs et al. 2002).

There is some error associated with the FRRF measurement of the parameters used in the calculation of primary productivity. Laney (2003) performed a detailed analysis of this measurement error, and suggested that at times it could be greater than the environmental variability in the FRRF parameters. Some of the error is not random, and will not be corrected by averaging or replicate sampling. The error results from both instrument biases and environmental factors. However, it is also not clear what the effect of the error on productivity calculations may be (Laney 2003). Such errors in assessing photosynthetic parameters may help to explain some of the variability in the observed relationship between the ${ }^{14} \mathrm{C}$ and FRRF techniques. If this is the case, future improvements in FRRF instrumentation, or the use of more robust techniques for determining photosynthetic parameters as suggested by Laney (2003) should improve the relationship between the FRRF and other productivity techniques.

Raateoja (2004) reported a curvilinear relationship between the FRRF- and ${ }^{14} \mathrm{C}$-based measurements of primary production. The departure from linearity gen- erally occurred above $200 \mu \mathrm{mol}$ quanta $\mathrm{m}^{-2} \mathrm{~s}^{-1}$, and appeared to be the result of the ${ }^{14} \mathrm{C}$ technique indicating $P_{\max }$ at a lower irradiance than the FRRF for the samples studied. We found that a simple linear model characterized the majority of our data well, and we did not observe a departure from linearity, indicating close agreement about when $P_{\max }$ was achieved. The results of Raateoja (2004) suggest that this type of agreement should not always be expected.

It should be noted that, while the ${ }^{14} \mathrm{C}$ method has been assumed to represent the 'true' value in this study, it is also subject to potential errors. Some potential sources of error include contamination of samples with metals or nutrients (Fitzwater et al. 1982), the question of whether ${ }^{14} \mathrm{C}$ is measuring gross or net productivity (Carpenter \& Lively 1980), container effects such as silica from sample vials stimulating diatoms and growth on container walls (Carpenter \& Lively 1980, Peterson 1980), and the difference in the degree of photoinhibition and photoadaptation from exposing cells to varying sunlight over the course of an entire day in nature versus shorter exposures to discrete and continuous light during laboratory studies (Peterson 1980). Many of the uncertainties in ${ }^{14} \mathrm{C}$ measurements, such as incubation time or light sources, would represent systematic errors, and so 2 studies that used ${ }^{14} \mathrm{C}$ may not be directly comparable if different incubation methods were used. For example, long in situ incubations versus short incubations under artificial light would be expected to give different results. For this same reason, any variations in the ${ }^{14} \mathrm{C}$ method used would have produced a different relationship to the FRRF data than was observed here.

These concerns with the ${ }^{14} \mathrm{C}$ technique point out a common problem with productivity measurements in general. It is difficult to compare productivity estimates between studies, because such estimates are always dependent on the method used. The reported differences in results from $\mathrm{O}_{2},{ }^{18} \mathrm{O}$, and ${ }^{14} \mathrm{C}$ methods (Oviatt et al. 1986, Grande et al. 1989) are similar to the differences found when comparing the FRRF and ${ }^{14} \mathrm{C}$ techniques. As stated above, even comparisons of ${ }^{14} \mathrm{C}$ measurements using different incubation methods can produce varying results. With this in mind, the FRRF results when compared to the ${ }^{14} \mathrm{C}$ results are remarkably consistent. The FRRF also has an advantage over traditional productivity measurement techniques, in that the measurements are performed in situ, thereby eliminating artifacts introduced by incubating samples in a container.

\section{Calibrating FRRF measurements}

Given the range of the FRRF: ${ }^{14} \mathrm{C}$ ratio illustrated in Fig. 3 and the uncertainty of some physiological con- 
stants assumed in the models, FRRF measurements should be calibrated against other established productivity techniques. Although there are uncertainties associated with all productivity estimates, calibrating the FRRF against another technique such as one using ${ }^{14} \mathrm{C}$ or ${ }^{18} \mathrm{O}$ provides an indirect method to correct for errors introduced when the assumptions made with the FRRF models differ from the true conditions. This provides a practical method to account for the current uncertainties associated with measuring primary production using fluorescence techniques. It also provides a basis for comparing FRRF productivity measurements to historical productivity estimates using different techniques, in order to assess long-term trends. The required frequency of calibrations would need to be determined on a case-by-case basis, depending on the environmental and biological variability within the system to be studied.

Moreover, the FRRF in combination with ${ }^{14} \mathrm{C}$ or ${ }^{18} \mathrm{O}$ productivity calibrations has advantages over using such techniques alone. The FRRF provides a way to increase spatial coverage in the areas between stations where traditional incubations are performed. In addition, large numbers of FRRF measurements over time and space will probably yield reasonable average values, since the slope between the ${ }^{14} \mathrm{C}$ and FRRF results seemed to vary consistently around a fixed range of slopes, making reasonable estimates of yearly productivity rates possible. Due to the greater frequency of measurements that the FRRF allows, such annual estimates may even be more robust than those produced using a smaller number of traditional phytoplankton incubations. Finally, given the uncertainties in other methods of measuring productivity, the FRRF is not necessarily less reliable, even if the results of the 2 techniques cannot be compared directly without performing a calibration.

Acknowledgements. We thank S. Whitford, K. Whitman, L. Reed, E. Swift, J. Yoder, and K. Killingbeck of the University of Rhode Island, G. Thursby of the U.S. EPA, T. Pucket of the R/V 'Cap'n Bert'. We also thank Z. Kolber for his assistance with the FRRF protocol. This research was funded under NOAA CMER Award No. NA07FE0425.

\section{LITERATURE CITED}

Behrenfeld MJ, Kolber ZS (1999) Widespread iron limitation of phytoplankton in the South Pacific Ocean. Science 243: 840-843

Behrenfeld MJ, Bale A, Kolber ZS, Aiken J, Falkowski PG (1996) Confirmation of iron limitation of photosynthesis in the equatorial Pacific Ocean. Nature 383:508-511

Berman MS, Sherman K (2001) A towed body sampler for monitoring marine ecosystems. Sea Technol 42(9):48-52

Boyd PW, Aiken J, Kolber ZS (1997) Comparison of radiocarbon and fluorescence based (pump and probe) measurements of phytoplankton photosynthetic characteristics in the Northeast Atlantic Ocean. Mar Ecol Prog Ser 149:215-226
Carpenter EJ, Lively JS (1980) Review of estimates of algal growth using ${ }^{14} \mathrm{C}$ tracer techniques. In: Falkowski PG (ed) Primary productivity in the sea. Plenum Press, New York, p 161-178

Dring MJ, Jewson DW (1982) What does ${ }^{14} \mathrm{C}$ uptake by phytoplankton really measure? Proc R Soc Lond B 214:351-368

Falkowski PG, Raven J (1997) Aquatic photosynthesis. Blackwell Science, Oxford

Fitzwater SE, Knauer GA, Martin JH (1982) Metal contamination and its effects on primary production measurements. Limnol Oceanogr 27:544-551

Fuchs E, Zimmerman RC, Jaffe JS (2002) The effect of elevated levels of phaeophytin in natural waters on variable fluorescence measured from phytoplankton. J Plankton Res 24:1221-1229

Gorbunov MY, Falkowski PG, Kolber ZS (2000) Measurement of photosynthetic parameters in benthic organisms in situ using a SCUBA-based fast repetition rate fluorometer. Limnol Oceanogr 45:242-245

Grande KD, Williams PJ, Marra J, Purdie DA, Heinemann K, Eppley RW, Bender ML (1989) Primary production in the North Pacific gyre: a comparison of rates determined by the ${ }^{14} \mathrm{C}, \mathrm{O}_{2}$ concentration and ${ }^{18} \mathrm{O}$ methods. Deep-Sea Res 36:1621-1634

Greene RM, Geider RJ, Falkowski PG (1991) Effect of iron limitation on photosynthesis in a marine diatom. Limnol Oceanogr 36:1772-1782

Kolber ZS, Falkowski PG (1993) Use of active fluorescence to estimate phytoplankton photosynthesis in situ. Limnol Oceanogr 38:1646-1665

Kolber ZS, Wyman KD, Falkowski PG (1990) Natural variability in photosynthetic energy conversion efficiency: a field study in the Gulf of Maine. Limnol Oceanogr 35:72-79

Kolber ZS, Barber RT, Coale KH, Fitzwater SE, Greene RM, Johnson KS, Lindley S, Falkowski PG (1994) Iron limitation of phytoplankton photosynthesis in the Equatorial Pacific Ocean. Nature 371:145-149

Kolber ZS, Prasil O, Falkowski PG (1998) Measurements of variable chlorophyll fluorescence using fast repetition rate techniques: defining methodology and experimental protocols. Biochim Biophys Acta 1367:88-106

Kromkamp JC, Forster RM (2003) The use of variable fluorescence measurements in aquatic ecosystems: differences between multiple and single turnover measuring protocols and suggested terminology. Eur J Phycol 38:103-112

Laney SR (2003) Assessing the error in photosynthetic properties determined by fast repetition rate fluorometry. Limnol Oceanogr 48:1646-1665

Oviatt CA, Rudnick DT, Keller AA, Sampou PA, Almquist GT (1986) A comparison of system $\left(\mathrm{O}_{2}\right.$ and $\left.\mathrm{CO}_{2}\right)$ and $\mathrm{C}-14$ measurements of metabolism in estuarine mesocosms. Mar Ecol Prog Ser 28:57-67

Oviatt CA, Keller AA, Reed L (2002) Annual primary production in Narragansett Bay with no bay-wide winter-spring phytoplankton bloom. Estuar Coast Shelf Sci 54:1013-1026

Parkhill J, Maillet G, Cullen JJ (2001) Fluorescence based maximal quantum yield for PSII as a diagnostic of nutrient stress. J Phycol 37:517-529

Peterson BJ (1980) Aquatic primary productivity and the ${ }^{14} \mathrm{CO}_{2}$ method: a history of the productivity problem. Annu Rev Ecol Syst 11:359-385

Platt T, Gullegoa CL, Harrison WG (1980) Photoinhibition of photosynthesis in natural assemblages of marine phytoplankton. J Mar Res 38:687-701

Raateoja MP (2004) Fast repetition rate fluorometry (FRRF) measuring phytoplankton productivity: a case study at the 
entrance to the Gulf of Finland, Baltic Sea. Boreal Environ Res 9:263-276

Sakshaug E, Bricaud A, Dandonneau Y, Falkowski PG and 5 others (1997) Parameters of photosynthesis: definitions, theory and interpretation of results. J Plankton Res 19:1637-1670

Smyth TJ, Pemberton KL, Aiken J, Geider RJ (2004) A methodology to determine primary production and phytoplankton photosynthetic parameters from Fast Repetition Rate Fluorometry. J Plankton Res 26:1337-1350

Steemann-Nielsen E (1952) The use of radio-active carbon (C14) for measuring organic production in the sea. J Cons Int Explor Mer 18:117-140

Strickland JDH, Parsons TR (1972) A practical handbook of seawater analysis, 2nd edn. Fisheries Research Board of Canada, Ottawa

Editorial responsibility: Kenneth Sherman (Contributing Editor), Narragansett, Rhode Island, USA
Suggett D, Kraay G, Holligan P, Davey M, Aiken J, Geider R (2001) Assessment of photosynthesis in a spring cyanobacterial bloom by use of a fast repetition rate fluorometer. Limnol Oceanogr 46:802-810

Suggett DJ, Oxborough K, Baker NR, Macintyre HL, Kana TM, Geider RJ (2003) Fast repetition rate and pulse amplitude modulation chlorophyll a fluorescence measurements for assessment of photosynthetic electron transport in marine phytoplankton. Eur J Phycol 38: 371-384

Suzuki K, Liu H, Saino T, Obata H, Takano M, Okamura K, Sohrin Y, Fujishima Y (2002) East-west gradients in the photosynthetic potential of phytoplankton and iron concentration in the subarctic Pacific Ocean during early summer. Limnol Oceanogr 47:1581-1594

Submitted: April 29, 2005; Accepted: September 9, 2005

Proofs received from author(s): March 3, 2006 